Original Article

\title{
EFFECT OF METFORMIN AND SIMVASTATIN IN DIAZEPAM-AND SODIUM NITRITE-INDUCED ANTEROGRADE AMNESIA IN MALE SWISS ALBINO MICE
}

\author{
S. S. TORGAL ${ }^{1 *}$, SUGATO C. H. ${ }^{1}$ \\ ${ }^{1}$ Department of Pharmacology and Pharmacotherapeutics, KLE's Jawaharlal Nehru Medical College, Belgaum 590010, Karnataka, India \\ Email: drtorgal@gmail.com
}

Received: 12 Apr 2017 Revised and Accepted: 20 Apr 2018

\begin{abstract}
Objective: To study the effect of metformin and simvastatin on diazepam-and sodium nitrite-induced anterograde amnesia in male Swiss albino mice.

Methods: A total of 56 healthy male Swiss albino mice weighing 20-30 g were included in the study Mice were divided into seven groups (n=8) and received a specific dosage of drugs including metformin and simvastatin. Anterograde amnesia was induced by diazepam and sodium nitrite. Morris water maze paradigm was used to study amnesia in which the mice were trained to locate a hidden platform by releasing them into the opaque water for four times a day for four consecutive days. The acquisition of this task was evaluated by measuring escape latency time on all the days of study and by measuring the index of retrieval on day 5 of the study. These observations were compared among the test groups and drug-induced amnesia groups. The time was expressed as mean \pm standard error of the mean.
\end{abstract}

Results: Significant reduction in the mean escape latency time $(25.25 \pm 5.09 \mathrm{~s})$ and index of retrieval ( $52.38 \pm 3.55 \mathrm{~s})$ was observed in groups administered with sodium nitrite and metformin $(p<0.001)$. In groups administered with sodium nitrite and simvastatin, the mean escape latency time and index of retrieval were $47.66 \pm 7.69 \mathrm{~s}$ and $40.75 \pm 4.13 \mathrm{~s}$, respectively $(p<0.05))$. In addition, metformin completely ameliorated sodium nitrite-induced anterograde amnesia.

Conclusion: Metformin and simvastatin ameliorated sodium nitrite-induced anterograde amnesia pointing toward a possible antioxidant role and can, therefore, be used to potentially inhibit oxidative stress-induced neurodegeneration. However, the pleiotropic roles of metformin and simvastatin are the areas that warrant further investigation before their clinical use.

Keywords: Anterograde amnesia, Metformin, Simvastatin, Diazepam, Sodium nitrite, Morris water maze

(C) 2018 The Authors. Published by Innovare Academic Sciences Pvt Ltd. This is an open access article under the CC BY license (http://creativecommons.org/licenses/by/4.0/) DOI: http://dx.doi.org/10.22159/ijpps.2018v10i6.19113

\section{INTRODUCTION}

Anterograde amnesia is a type of memory loss due to impairment in the medial temporal lobe of the brain involved in the retention of memory. The condition of anterograde amnesia renders the person incapable of storing, retaining, and recalling the memories of recent events [1]. It can also be one of the symptoms or conditions in earlier stages of dementia [2].

Psychogenic (due to stress or trauma) or biological (insufficient cerebral circulation, substance abuse, and brain diseases) can contribute to the development of amnesia. Neuronal degeneration in the medial temporal lobe occurs mainly due to biological factors and is the main focus of treatment in the recent times [3]. Various hypotheses of pathologies leading to neuronal death in amnesia have been proposed such as amyloid cascade hypothesis, tau hypothesis, excitotoxicity, inflammatory hypothesis, oxidative stress hypothesis, vascular hypothesis, cholesterol hypothesis, and diabetes and abnormal insulin signalling hypothesis [4]. However, recent research has documented the presence of stem cells (neural precursor) in the brain [5] and this neurogenesis in the hippocampus is reported to play an important role in the abilities of an individual, especially in learning and memory [5, 6]. Hence, pharmacotherapy of amnesia can be directed either at neuroprotection or promoting neurogenesis.

Drugs such as N-methyl-D-aspartate (NMDA) antagonists, acetylcholinesterase inhibitors, and nootropics have been indicated to be mostly beneficial in improving symptoms of cognitive disorders such as dementia due to Alzheimer's disease, vascular dementia, senile dementia, which predominantly affects the elderly population [6, 7]. More scientific research is required to develop efficacious and safe drugs for amnesia treatment, particularly to evaluate additional mechanisms of safeguarding neurogenesis, as these drugs are unable to arrest the pathologies of amnesia or treat them to complete remission $[7,8]$.
In this continuum, many drugs are being tested for the treatment of amnesia, such as statins, nonsteroidal anti-inflammatory drugs (NSAIDs), omega 3 fatty acids, vitamins [9, 10]. Diabetes mellitus (DM) and dyslipidemia are among the modifiable risk factors for the neurodegenerative disease $[11,12]$. They have been associated with increased risk of cognitive impairment and dementias, both individually and collectively [12-15]. The drug, such as metformin, is widely used in the treatment of type II DM, as it sensitizes the tissues to insulin [16]. It is also being tested for its use in treating anterograde amnesia. Wang et al. [17] have demonstrated the beneficial effects of metformin in reducing neuritic plaques and tangles. This could be attributed to reduced hyperglycemia and insulin resistance [18] on metformin use. Wang et al. also reported the metformin activity of promoting neurogenesis and spatial memory formation [17]. However, in a multicentric randomized clinical trial, intensive control of hyperglycemia failed to show any significant cognitive improvement [19]. This finding definitely warrants a review of metformin's additional mechanism of action. In view of this inconclusive and limited literature, this study is planned to explore and substantiate the effects of metformin in an animal model of induced amnesia. A further attempt has been made to delineate the mechanism for the same.

On the other hand, statins have been known to be used in the treatment of dyslipidemia (one of the risk factors for Alzheimer's dementia) [12]. It has been proposed that hypercholesterolemia leads to $\beta$ amyloid generation [20-22]. However, preclinical studies have not only found a decrease in $\beta$ amyloid but reductions in inflammation and oxidant generation with the use of statin as well $[23,24]$. It would, therefore, be prudent to know whether statins ameliorate neuropathologies of dementia by reducing cholesterol levels, or by additional pleiotropic actions [25]. In this study, an attempt has been made to screen the pleiotropic effects of lipophilic statin and simvastatin on varied mechanisms of induced amnesia.

In this study, the use of diazepam and sodium nitrite is rationalized by the fact that these are pharmacological agents to induce amnesia. 
As there is a lacuna in studies with respect to use of metformin and simvastatin in treating diazepam and sodium nitrite-induced anterograde amnesia, the present study was undertaken with an objective to investigate the roles of metformin and simvastatin on diazepam-and sodium nitrite-induced anterograde in male Swiss albino mice.

\section{MATERIALS AND METHODS}

\section{Test animals}

Adult male Swiss albino mice weighing $25 \pm 5 \mathrm{~g}$ were selected on the basis of their swimming ability. The selected mice were secured from the central animal house of J. N. Medical College, Belgaum. The study was ratified by Institutional animal ethical committee (IAEC), constituted as per the guidelines of Committee for the purpose of control and supervision of experiments on Animals (CPCSEA), New Delhi (MDC/AH/3(1)).

The mice were sustained on standard rat chow pellet (Amrut Brand) and water ad libitum and were acclimatized for $10 \mathrm{~d}$ to a photoperiod of $12 \mathrm{~h}$, before carrying out the experiments. Subsequently, they were divided into seven groups including eight mice in each group. Each of the groups received a specific dosage of the drugs as described in table 1 .

Table 1: Categorization of mice and dosage of drug in each group

\begin{tabular}{ll}
\hline Groups & Drugs for acquisition trial \\
\hline I & Distilled water $(10 \mathrm{mg} / \mathrm{kg}$, i. p) 30 min before trials \\
II & Diazepam $(1 \mathrm{mg} / \mathrm{kg}$, i. p) $30 \mathrm{~min}$ before trials $[26,27]$ \\
III & Sodium nitrite $(75 \mathrm{mg} / \mathrm{kg}$, i. p) 30 min before trials [28] \\
IV & Diazepam $(1 \mathrm{mg} / \mathrm{kg}) 30 \mathrm{~min}$ before trials+metformin $(200 \mathrm{mg} / \mathrm{kg}$ oral $) 60 \mathrm{~min}$ before trials [17] \\
V & Sodium nitrite $(75 \mathrm{mg} / \mathrm{kg}) 30$ min before trials+metformin $(200 \mathrm{mg} / \mathrm{kg}) 60 \mathrm{~min}$ before trials \\
VI & Diazepam $(1 \mathrm{mg} / \mathrm{kg}) 30 \mathrm{~min}$ before trials+simvastatin $(5 \mathrm{mg} / \mathrm{kg}$ oral $) 60 \mathrm{~min}$ before trials \\
VII & Sodium nitrite $(75 \mathrm{mg} / \mathrm{kg}) 30$ min before trials+simvastatin $(5 \mathrm{mg} / \mathrm{kg}) 60 \mathrm{~min}$ before trials \\
\hline
\end{tabular}

i. p. Intraperitoneally

\section{Chemicals}

Diazepam (Valium, $5 \mathrm{mg}$ ) was purchased from the hospital pharmacy whereas sodium nitrite was obtained from Anmol Chemicals Pvt. Ltd., Gujarat. The test drugs-metformin (Glycomet, $500 \mathrm{mg}$ ) and simvastatin (Zocur, $10 \mathrm{mg}$ ) were procured from USV pharmaceuticals and Merck pharmaceuticals, respectively.

\section{Preparation}

Suspensions of diazepam and simvastatin were prepared in gum acacia and sterile distilled water $[26,27]$. On the other hand, sodium nitrite and metformin preparations were made in sterile distilled water prior to administration.

\section{Administration}

Diazepam and sodium nitrite were administered by injection (intraperitoneally) in the selected mice whereas metformin and simvastatin were administered orally.

\section{Morris water maze}

The spatial learning and memory of the mice were analysed by an exteroceptive behavioural paradigm, the Morris water maze, as described by Bromley-Brits et al. [29]. The method was slightly modified by dividing the circular tank into quadrants with the help of a wire wherein one of the quadrants (goal quadrant-Qg) had the presence of a platform $(29 \mathrm{~cm}$ high $)$ at the center. The position of the platform was fixed and water was made opaque by the addition of 3 $\mathrm{L}$ of milk, throughout the acquisition trial. The days of the experiment were categorized into-training (day 1), acquisition trial (day 2-5) and retrieval trial (day 6). Similar test conditions were maintained for all the test groups.

\section{Training for trial}

The mice were familiarized with an escape route from the aversive stimuli (water), prior to the initialization of the trial.

\section{Acquisition trial}

Mice (control and drug-treated) were released into the water, in one of the quadrants $(Q)$, for four consecutive days. They were subjected to four trials per day, with the subsequent trial being held only after completion of the ongoing trial. All the eight mice were subjected to to trial in the same Q. During successive trials and days, starting points were changed as described in table 2 . The dosage of drugs administered to each of the groups is described in table 1.

Table 2: Order of the release of mice in specific quadrants

\begin{tabular}{lllll}
\hline Days & Firsttrial & Second trial & Third trial & Fourth trial \\
\hline 1 & Q1 & Q2 & Q3 & Qg \\
2 & Q2 & Q3 & Qg & Q1 \\
3 & Q3 & Qg & Q1 & Q2 \\
4 & Qg & Q1 & Q3 \\
\hline
\end{tabular}

Q, Quadrants; Qg, goal quadrant

Since the mice were required to locate the hidden platform by "hit and trial' method with the help of distal cues, several such cues were provided to the mice with strict adherence to their same fixity for all the days of the trial. Even the position of the examiner was fixed with respect to the distal cues. Subsequently, they were allowed to escape to the platform and stay there for $20 \mathrm{~s}$ (to generate a spatial memory of the hidden platform with the help of distal cues). The time required to escape to the platform, escape latency time (ELT), was noted and compared among different days and different groups. Mice unable to locate the platform within $120 \mathrm{~s}$ were guided to the platform by hand and again kept there for $20 \mathrm{~s}$. However, mice failing the task on consecutive trials for two successive days were excluded from the study.
Retrieval trial: On day 6 of study, the platform was removed from Qg and the time spent in Qg (index of retrieval-IOR) was evaluated for all the groups of mice, that is among control, drug-induced amnesia, and drug-treated groups. This was done only once and the farthest quadrant (quadrant remained same for all the groups) from the Qg was selected to release the mice. Prior to the trial, all groups were administered with sterile distilled water $30 \mathrm{~min}$ before the trial.

\section{Statistical analysis}

Data obtained were analysed by one-way analysis of variance (ANOVA) followed by Dunnett's test using Graph Pad Prism software. Data were expressed as mean \pm standard error of the mean (SEM) and $P \leq 0.05$ was considered statistically significant. 


\section{RESULTS}

\section{Morris water maze}

The data obtained from the experiment along with the IOR were categorized into different groups on the basis of the drugs administered as tabulated in table 3 .

\section{Control group}

ELT on day 4 was less when compared to that of day 1 indicating the ability of mice to rapidly learn and acquire the task of locating the submerged platform. Moreover, the trajectory toward Qg changed from circumferential on day 1 to goal-directed on the day 4 . Thus, upon removing the platform, it was concluded that they could retrieve the previous location by spending more time in the Qg.

Diazepam-and sodium nitrite-induced anterograde amnesia: No significant difference was observed in ELT upon calculation of mean ELT, indicating the failure of diazepam-treated mice group and sodium nitrite-treated mice group to acquire the task. The mice in the two groups were found to swim circumferentially with minimal goal-directed behaviour even on day 4 of the trial indicating poor retention of the memory of the location of the hidden platform.

In the group IV with the administration of metformin 30 min before diazepam, the acquisition of the task was unsatisfactory with not significant results. In contrast, metformin was found to ameliorate the effects of sodium nitrite when administered $30 \mathrm{~min}$ before the administration of sodium nitrite. A significant difference $(p<0.001)$ was observed IOR along with the difference in the mean ELT of day 4 compared the day 1 . In addition, their trajectories were increasingly goal-directed. On the day 6 , the mice spent the majority of their swimming time locating for the missing platform in the $\mathrm{Qg}$.

Similarly, simvastatin was observed to be ineffective in ameliorating the effects of diazepam in group VI. When administered before sodium nitrite in group VII, no significant difference was observed in the ELT of day 4 compared to the ELT of day 1 . However, the mice did search for the hidden platform as evidenced by the decrease in ELT on the day 4. Additionally, as evident on day 6, mice demonstrated retrieval of the learnt task by spending maximum time in the previously Qg. Their IOR was significantly $(p<0.05)$ different from group III, where only sodium nitrite was administered to them.

Table 3: Mean escape latency time and index of retrieval for Morris water maze

\begin{tabular}{|c|c|c|c|c|c|}
\hline \multirow[t]{2}{*}{$\operatorname{Groups}(n=8)$} & \multicolumn{4}{|c|}{ ELT in seconds (mean \pm SEM) } & \multirow[t]{2}{*}{ Index of retrieval in seconds } \\
\hline & Day 1 & Day 2 & Day 3 & Day 4 & \\
\hline I & $79.53 \pm 5.37$ & $62.64 \pm 6.60$ & $48.53 \pm 5.66$ & $31.63 \pm 3.25$ & $39.38 \pm 4.71$ \\
\hline II & $69.94 \pm 5.79$ & $58.34 \pm 7.27$ & $55.28 \pm 4.56$ & $59.31 \pm 4.87$ & $25.63 \pm 4.09$ \\
\hline III & $60.38 \pm 6.24$ & $54.44 \pm 5.71$ & $54.22 \pm 5.29$ & $57.09 \pm 5.3$ & $24.75 \pm 3.4$ \\
\hline IV & $53.16 \pm 11.17$ & $51.25 \pm 11.91$ & $48.71 \pm 8.25$ & $51 \pm 8.99$ & $28.38 \pm 3.70$ \\
\hline V & $61.41 \pm 6.75$ & $35.5 \pm 8.06$ & $28.59 \pm 6.8$ & $25.25 \pm 5.09$ & $52.38 \pm 3.55^{* *}$ \\
\hline VI & $66.69 \pm 8.07$ & $42.47 \pm 10.65$ & $59.5 \pm 6.59$ & $51.69 \pm 8.34$ & $24.63 \pm 3.43$ \\
\hline VII & $66.72 \pm 10.91$ & $63.78 \pm 9.06$ & $65.94 \pm 5.64$ & $47.66 \pm 7.69$ & $40.75 \pm 4.13^{*}$ \\
\hline
\end{tabular}

${ }^{*} p<0.05 ;{ }^{* *} p<0.001$; Data represented as mean \pm SEM; ELT: escape latency time; $\mathrm{N}=2$

\section{DISCUSSION}

In this study, the effect of metformin and simvastatin on druginduced anterograde amnesia in adult male Swiss albino mice was studied.

Metformin and simvastatin are among the most commonly prescribed and best-selling drugs, which have brought about dramatic changes in the prevalence of metabolic diseases. These drugs have shown benefits beyond their expected indications. Researchers have thus attributed this wide spectrum of indications to their pleiotropic actions. A possible role in neuroprotection and/or neurogenesis would offer a hope in managing otherwise irreversible neurodegenerative conditions along with the added benefits of improving the quality of life in the geriatric population.

In this study, anterograde amnesia was induced with the help of diazepam and sodium nitrite. Diazepam and sodium nitrite affected both the learning and retrieval activities of the mice in the trials. These drugs have been used numerous times for studying the effects of drugs in experimental amnesia. Diazepam, a prototypal benzodiazepine, facilitates gamma-amino butyric acid (GABA); major neurotransmitter involved in learning and memory, binding to $\mathrm{GABA}_{\mathrm{A}}$ subunit of GABA receptors and bring about inhibition of most neurotransmission in the central nervous system (CNS). It has been postulated that binding to $\alpha 1$ subunit of $\mathrm{GABA}_{\mathrm{A}}$ receptor results in amnesia, as observed with the use of benzodiazepines [30, 31]. Hence, diazepam finds application as a preanesthetic medicine due to its ability to cause anterograde amnesia. Diazepam has also been used in various animal studies to induce amnesia [26, 32].

On the other hand, sodium nitrite, by induction of chemical hypoxia [33], causes hypoxic neuronal injury. The administration of sodium nitrite is known to result in the conversion of haemoglobin to methemoglobin thereby reducing oxygen-carrying capacity of the blood. Schindler et al. [34] had reviewed the validity of this method for manipulating brain energy metabolism. Sodium nitrite can also act by causing oxidative injury to neurons by forming peroxynitrates
[33]. In another study by Bhattacharya[35],cognitive deficits in rats were induced by administering sodium nitrite $(75 \mathrm{mg} / \mathrm{kg}$, subcutaneously) while studying the zootropic effect of BR16A (Mentat). In the current study, the doses of diazepam and sodium nitrite had been selected on the basis of literature $[26,27,32]$.

The paradigm used for studying effects of metformin and simvastatin on the condition of anterograde amnesia was Morris water maze [36, 37], as it is considered the 'gold standard' for hippocampal function assessment. The structure of the hippocampus is conserved across the mammals, which made the mice hippocampus suitable model for the study of human hippocampaldependent processes [37]. Mice, as all rodents, have been known to have a deep sense of spatial memory and thus, Morris water maze serves as a natural motivation for them [37]. The other advantages of the paradigm are that it decreases possible bias due to the scent of the previous animal, and since it is an open field test, no directionspecific behaviour needs to be induced [37]. Moreover, mice are better performers, as they have lesser tendencies to float than other animal subjects used in studies.

This study is first of its kind in studying the effect of metformin on diazepam-induced amnesia. However, it was observed from the study that both metformin and simvastatin failed to ameliorate the amnesia caused due to diazepam, which raised doubts on the ability of metformin to cross blood-brain barrier (BBB). However, reports including that of that of Barker et al. support the ability of metformin to cross BBB in adequate concentration [38], wherein they quantified metformin levels in the brain regions and the cerebrospinal fluid by High-performance liquid chromatography. On the other hand, Wang et al. showed that metformin in addition to promoting neurogenesis also improved spatial memory formation in mice [17]. As there was no evident spatial memory formation in the acquisition trials, perhaps GABA inhibitory neurons inhibited spatial memory formation. This also proves that diazepam caused amnesia via GABA neuronal inhibition of memory processes.

From the current study, it was also found that metformin ameliorated the sodium nitrite-induced amnesia. This could suggest 
the ability of metformin to inhibit oxidation of haemoglobin by sodium nitrite in the blood. Hence metformin could produce its effects without the need of crossing the BBB. The possible role of metformin as a neuronal antioxidant, promoting neurogenesis, or enhancing spatial memory formation may be some other reasons for the significant results [17, 39-41].

Simvastatin is a potent lipophilic statin [42] and was thus selected as it would easily cross the BBB as evidenced by Bettermann et al. They observed that the lipophilic statins tended to reduce dementia risk more than non-lipophilic agents [43]. As evident from the current study, simvastatin did not show any beneficial effect in diazepaminduced anterograde amnesia as it does not have any effect on GABAergic transmission or upregulating neurotransmitters involved in memory processes.

Simvastatin, when administered before sodium nitrite on day 4 of acquisition trial, showeda decrease in ELT. However, this difference was not significant, similar to the reports of Sano et al.[44].

Statins have been shown to have antioxidant and anti-inflammatory properties [45]. Zhu et al.[40] and Keller et al.[46] have reported that oxidative stress and inflammation are tightly linked to the pathogenesis and development of Alzheimer's disease [47] and also to mild cognitive impairment (MCI) [46]. Statins act by blocking the isoprenylation and thereby the downstream activation of members of the Rho family, such as RhoA and Rac1, which stimulates Nicotinamide adenine dinucleotide phosphate (NADP) oxidase-a major source of reactive oxygen species (ROS) [48].

The present study found a definite role of metformin and the possible role of simvastatin in ameliorating the sodium nitriteinduced anterograde amnesia. An obvious next step would be a demonstration of hypoxic injury to the brain by using pathologic and neuroimaging techniques and then exploring the effects of these drugs. Matson, in his review, had suggested the role of oxidative stress in neurodegeneration [49]. Oxidative stress even may be the initial cause of neuronal damage [47]. Also, in process of aging, ROS production increases and ability to fight them decreases. Hence, metformin and simvastatin, which are usually started in midlife [50, 51], can arrest the process of neurodegeneration at its start and bring down the prevalence of cognitive impairment.

Alternatively, any observational or randomized studies exploring the effect of these drugs on dementia in elderly people should take the long-term usage of concomitant benzodiazepines into account [49]. Also, the studies showing inconsistent results should be re-evaluated for use of benzodiazepines [52].

\section{CONCLUSION}

Thus,it could be suggested from the present study that metformin and simvastatin, with their repertoire of pleiotropic effects, might offer benefit in the management of neurodegenerative disorders and its symptoms. This study also indicates a possible antioxidant role of metformin and simvastatin in arresting neurodegeneration in amnesia, which will open new avenues in the management of a number of neurodegenerative disorders of the brain.

\section{ACKNOWLEDGEMENT}

None

\section{AUTHORS CONTRIBUTIONS}

SST designed the study and prepared the manuscript. CHS acquired and analyzed the data and prepared the initial draft of the manuscript.

\section{CONFLICT OF INTERESTS}

We have no conflict of interest to declare

\section{REFERENCES}

1. Gazzaniga M, Ivry R, Mangun G. Cognitive neuroscience: the biology of the mind. New York: W. W. Norton and Company; 2009.

2. McCance KL, Huether SE, Parkinson C. Pathophysiology: The Biological Basis for Disease in Adults and Children. US: Mosby, Inc.; 2010. p. 106.
3. Kopelman MD. Disorders of memory. Brain 2002;125:2152-90.

4. Mohandas E, Rajmohan V, Raghunath B. Neurobiology of Alzheimer's disease. Indian J Psychiatry 2009;51:55-61.

5. Zhao C, Deng W, Gage FH. Mechanisms and functional implications of adult neurogenesis. Cell 2008;132:645-60.

6. Rang HP, Flower RJ, Henderson G. Rang and Dale's Pharmacology. $7^{\text {th }}$ ed. London: Churchill livingstone, Elsevier; 2007. p. 14

7. Tripathi KD. Essentials of Medical Pharmacology. 7th ed. New Delhi: Jaypee brothers medical Publishers; 2010. p. 5.

8. Standaert DG, Roberson ED. Goodman and Gilman's The Pharmacological Basis of Therapeutics.12 $2^{\text {th }}$ ed. New Delhi: McGraw Hill, Medical; 2011. p. 19.

9. Cole GM, Morihara T, Lim GP, Yang F, Begum A, Frautschy SA. NSAID and antioxidant prevention of Alzheimer's disease: lessons from in vitro and animal models. Ann N Y Acad Sci 2004;1035:68-84.

10. Labrousse VF, Nadjar A, Joffre C, Costes L, Aubert A, Gregoire S, et al. Short-term long chain omega3 diet protects from neuroinflammatory processes and memory impairment in aged mice. PLoS One 2012;7:e36861.

11. Nair G, Van Dyk K, Shah U, Purohit DP, Pinto C, Shah AB, et al. Characterizing cognitive deficits and dementia in an aging urban population in India. Int J Alzheimers Dis 2012:8. http://dx.doi.org/10.1155/2012/673849

12. Shaji KS, Jotheeswaran AT, Girish N, Bharath $\mathrm{S}$, Dias $\mathrm{A}$, Pattabiraman M, et al. The dementia india report 2010: prevalence, impact, costsandservicesfordementia. New Delhi: Alzheimer's and Related Disorders Society of India: Available from: 2010. http://www.alzheimer.org.in/assets/dementia.pdf [Last accessed on 10 Mar 2017]

13. Carlsson CM. Type 2 diabetes mellitus, dyslipidemia, and Alzheimer's disease. J Alzheimers Dis 2010;20:711-22.

14. Cukierman Yaffe T, Gerstein HC, Williamson JD, Lazar RM, Lovato L, Miller ME, et al. Relationship between baseline glycemic control and cognitive function in individuals with type 2 diabetes and other cardiovascular risk factors: the action to control cardiovascular risk in diabetes-memory in diabetes (ACCORD-MIND) trial. Diab Care 2009;32:221-6.

15. Luchsinger JA, Reitz C, Patel B, Tang MX, Manly JJ, Mayeux R. Relation of diabetes to mild cognitive impairment. Arch Neurol 2007;64:570-5.

16. Powers AC, D'Alessio D. Goodman and Gilman's The Pharmacological Basis of Therapeutics. 12 ed. Brunton L CB, Knollman B. editor. New York: McGraw-Hill; 1996. p. 19.

17. Wang J, Gallagher D, DeVito LM, Cancino GI, Tsui D, He L, et al. Metformin activates an atypical PKC-CBP pathway to promote neurogenesis and enhance spatial memory formation. Cell Stem Cell 2012;11:23-35.

18. Beeri MS, Schmeidler J, Silverman JM, Gandy S, Wysocki M, Hannigan CM, et al. Insulin in combination with other diabetes medication is associated with less Alzheimer neuropathology. Neurology 2008;71:750-7.

19. Launer LJ, Miller ME, Williamson JD, Lazar RM, Gerstein HC, Murray AM, et al. Effects of intensive glucose lowering on brain structure and function in people with type 2 diabetes (ACCORD MIND): a randomised open-label substudy. Lancet Neurol 2011;10:969-77.

20. Andrade C, Radhakrishnan R. The prevention and treatment of cognitive decline and dementia: An overview of recent research on experimental treatments. Indian J Psychiatry 2009;51:12-25.

21. Ghribi 0. Potential mechanisms linking cholesterol to Alzheimer's disease-like pathology in rabbit brain, hippocampal organotypic slices, and skeletal muscle. J Alzheimers Dis 2008;15:673-84.

22. Barone E, Di Domenico F, Butterfield DA. Statins more than cholesterol-lowering agents in Alzheimer disease: their pleiotropic functions as potential therapeutic targets. Biochem Pharmacol 2014;88:605-16.

23. Li G, Larson EB, Sonnen JA, Shofer JB, Petrie EC, Schantz A, et al. Statin therapy is associated with reduced neuropathologic changes of Alzheimer disease. Neurology 2007;69:878-85.

24. Boimel M, Grigoriadis N, Lourbopoulos A, Touloumi O, Rosenmann D, Abramsky 0 , et al. Statins reduce the 
neurofibrillary tangle burden in a mouse model of tauopathy. J Neuropathol Exp Neurol 2009;68:314-25.

25. Tandon V, Bano G, Khajuria V, Parihar A, Gupta S. Pleiotropic effects of statins. Indian J Pharmacol 2005;37:77.

26. Dhingra D, Kumar V. Memory-enhancing activity of palmatine in mice using elevated plus maze and morris water maze. Adv Pharmacol Sci 2012:1-7. http://dx.doi.org/10.1155/2012/ 357368

27. Myhrer T. Neurotransmitter systems involved in learning and memory in the rat: a meta-analysis based on studies of four behavioral tasks. Brain Res Brain Res Rev 2003;41:268-87.

28. Mihic SJ, Harris RA. Goodman and Gilman's The Pharmacological Basis of Therapeutics. Brunton L CB, Knollman B. editor. New Delhi: McGraw Hill Medical; 2011. p. 23.

29. Bromley Brits K, Deng Y, Song W. Morris water maze test for learning and memory deficits in Alzheimer's disease model mice. J Vis Exp 2011;53. Doi:10.3791/2920.

30. Mihic SJ, Harris RA. Goodman and Gilman's The Pharmacological Basis of Therapeutics. 12 th ed ed. Brunton LCB, Knollman B. editor. New Delhi: McGraw Hill Medical; 2011. p. 24.

31. Savic MM, Obradovic DI, Ugrešic ND, Bokonjic DR. Memory effects of benzodiazepines: Memory stages and types versus binding-site subtypes. Neural Plast 2005;12:289-98.

32. Porsolt RD, Lenegre A, Avril I, Doumont G. Antagonism by exifone, a new cognitive enhancing agent, of the amnesias induced by four benzodiazepines in mice. Psychopharmacology (Berl) 1988;95:291-7.

33. Hlinak Z, Krejci I, Hondlik J, Yamamoto A. Behavioral consequences of sodium nitrite hypoxia in male rats: Amelioration with alaptide treatment. Methods Find Exp Clin Pharmacol 1990;12:385-93.

34. Schindler U, Rush DK, Fielding S. Nootropic drugs: animal models for studying effects on cognition. Drug Dev Res 1984;4:567-76.

35. Bhattacharya SK. Nootropic effect of BR-16A (Mentat), a psychotropic herbal formulation, on cognitive deficits induced by prenatal undernutrition, postnatal environmental impoverishment and hypoxia in rats. Indian J Exp Biol 1994;32:31-6.

36. Morris R. Developments of a water-maze procedure for studying spatial learning in the rat. J Neurosci Methods 1984;11:47-60.
37. Maei HR, Zaslavsky K, Teixeira CM, Frankland PW. What is the most sensitive measure of water maze probe test performance? Front Integr Neurosci 2009;3:4.

38. Barker MJ, Greenwood KM, Jackson M, Crowe SF. Cognitive effects of long-term benzodiazepine use: a meta-analysis. CNS Drugs 2004;18:37-48.

39. Maric A. Metformin-more than 'gold standard' in the treatment of type 2 diabetes mellitus. Diabetologia Croatica 2010;39:9.

40. Zhu X, Lee HG, Perry G, Smith MA. Alzheimer disease, the twohit hypothesis: an update. Biochim Biophys Acta 2007;1772:494-502.

41. Salminen A, Hyttinen JM, Kaarniranta K. AMP-activated protein kinase inhibits NF-kappaB signalling and inflammation: impact on healthspan and lifespan. J Mol Med (Berl) 2011;89:667-76.

42. Bersot TP. Goodman and gilman's the pharmacological basis of therapeutics. 12 ed. Brunton LCB, Knollman B. editor. New Delhi: McGraw Hill Medical; 2011. p. 877-908.

43. Nakagami H, Jensen KS, Liao JK. A novel pleiotropic effect of statins: prevention of cardiac hypertrophy by cholesterolindependent mechanisms. Ann Med 2003;35:398-403.

44. Sano M, Bell KL, Galasko D, Galvin JE, Thomas RG, van Dyck CH, et al. A randomized, double-blind, placebo-controlled trial of simvastatin to treat Alzheimer disease. Neurology 2011; 77:556-63.

45. Albert MA, Danielson E, Rifai N, Ridker PM, Investigators P. Effect of statin therapy on C-reactive protein levels: the pravastatin inflammation/CRP evaluation (PRINCE): a randomized trial and cohort study. JAMA 2001;286:64-70.

46. Keller JN, Schmitt FA, Scheff SW, Ding Q, Chen Q, Butterfield DA, et al. Evidence of increased oxidative damage in subjects with mild cognitive impairment. Neurology 2005;64:1152-6.

47. Nunomura A, Perry G, Aliev G, Hirai K, Takeda A, Balraj EK, et al. Oxidative damage is the earliest event in Alzheimer disease. J Neuropathol Exp Neurol 2001;60:759-67.

48. Oka M, Fagan KA, Jones PL, McMurtry IF. Therapeutic potential of RhoA/Rho kinase inhibitors in pulmonary hypertension. $\mathrm{Br} \mathrm{J}$ Pharmacol 2008;155:444-54.

49. Mattson MP. Apoptosis in neurodegenerative disorders. Nat Rev Mol Cell Biol 2000;1:120-9.

50. Hadidchi MS, Shenoy UV, Thomas JM, Vupputuri RS. Study of awareness among healthcare providers for the need to periodically screen renal functions in diabetic patients receiving metformin. Int J Curr Pharm Res 2015;7:51-3. 